\title{
Prevalence and Associated Factors of Tooth Erosion in 8 -12-Year- Old Brazilian Schoolchildren
}

\author{
Mabel Miluska Suca Salas*/ Fabiana Vargas-Ferreira**/ Thiago Machado Ardenghi***/ Karen Glazer \\ Peres****/ Marie-Charlotte DNJM Huysmans*****/ Flávio Fernando Demarco******
}

\begin{abstract}
Objective: This study estimated the prevalence, distribution and associated factors of tooth erosion in Brazilian schoolchildren. Study design: A cross-sectional study was carried out in a representative sample of children aged 8-12-years-old from public and private schools. Six calibrated examiners assessed tooth erosion ( $O$ 'Sullivan index) and other oral conditions (dental trauma, enamel defects, plaque, dental caries and dental crowding). Socio-demographic and behavioral data were collected using questionnaires. Interviews were conducted in children and in parents. Data were analyzed using Poisson regression model considering the cluster sample (Prevalence Ratio-PR; 95\% Confidence Interval-CI). Results: A total of 1,210 children participated and were examined. Tooth erosion was observed in $25.1 \%$ of the children. Lesions were mostly observed in enamel and less than a half of the buccal surface was affected. The type of school and age were significant associated with higher prevalence of tooth erosion and dental crowding was associated with less probability of tooth erosion significantly. Acidic food or drinks were not associated with dental erosion. Conclusion: The prevalence of tooth erosion in the studied population was high. Erosive lesions were not severe, confined in enamel. Tooth erosion was associated with age, type of school, socioeconomic level and dental crowding.
\end{abstract}

Key words: tooth erosion, prevalence, child, adolescent, epidemiology

* Mabel Miluska Suca Salas, DDS, MSc, PhD, Post-Graduate Program in Dentistry, Universidade Federal de Pelotas, Brazil, Associate Professor, Graduate Program in Dentistry, Science Faculty of Tocantins, Brazil.

** Fabiana Vargas-Ferreira, DDS, MSc, PhD, Post-Graduate Program in Dentistry, Universidade Luterana do Brasil, Canoas, Brazil.

*** Thiago Machado Ardenghi, DDS, MSc, PhD, Associate Professor, Post-Graduate Program in Dentistry, Universidade Federal de Santa Maria, Brazil.

**** Karen Glazer Peres, DDS, MSc, PhD, Associate Professor, Post-Graduate Program in Dentistry, University of Adelaide, Australia.

***** Marie-Charlotte D.N.J.M. Huysmans, DDS, MSc, PhD, Professor, Department of Restorative and Preventive Dentistry, Radboud University Nijmegen Medical Centre, Nijmegen, The Netherlands.

****** Flavio Fernando Demarco, DDS, MSc, PhD, Professor, Post-Graduate Program in Dentistry, Post-Graduate Program in Epidemiology, Universidade Federal de Pelotas, Pelotas, Brazil.

Send all correspondence to:

Flávio Fernando Demarco - Universidade Federal de Pelotas, School of Dentistry, Gonçalves Chaves, 457, zip code 96015568, Pelotas-RS, Brazil . Phone: 5332226690

E-mail: ffdemarco@gmail.com

\section{INTRODUCTION}

$\Lambda$ $\mathrm{n}$ increased frequency of tooth erosion has been detected in adolescents ${ }^{1-3}$ and seems to be a growing problem ${ }^{3}$. Tooth erosion is induced by non-bacterial acids, which may be acquired from extrinsic sources, like diet or medication, ${ }^{2}$ or by intrinsic acid through vomiting or reflux. ${ }^{4}$ Tooth erosion is an irreversible and cumulative condition ${ }^{5}$ and it is frequently observed with other types of wear. 1,5 Delayed or inadequate diagnosis with a lack of preventive intervention ${ }^{6}$ could lead to advanced tissue loss ${ }^{7}$ compromising tooth vitality, functionality or aesthetics. ${ }^{2}$

Cross-sectional investigations, conducted in children with permanent dentition found variation in the prevalence of tooth erosion, ranging from $7.2 \%$ to $95 \% .{ }^{3}, 5-14$ Brazilian studies conducted in children showed

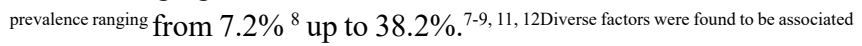
with the presence of tooth erosion, 7 making this a complex condition. ${ }^{6}$ In children, extrinsic factors may influence tooth erosion presence, even though intrinsic acids should be also considered. ${ }^{2}$ Soft drink consumption has been linked to tooth erosion. ${ }^{10}$ Frequency,,${ }^{1,2,14}$ contact time ${ }^{13}$ and unusual patterns of food or drinks consumption ${ }^{14}$ have been reported as factors in tooth erosion. Socioeconomic and demographic factors have also been reported, but results are contradictory. While some studies have found higher prevalence of tooth erosion in families with lower income ${ }^{2,6}$, other studies showed higher tooth erosion prevalence in children from wealthy families ${ }^{2}$, attending private schools ${ }^{12}$, or from mothers with higher education level ${ }^{14}$. Behavioral and biological conditions, including the frequency of tooth brushing ${ }^{14}$, plaque presence ${ }^{1,14}$, presence of enamel defects 
${ }^{5,8}$, malocclusion ${ }^{1,5}$, dental caries ${ }^{5}$, gastric upsets ${ }^{6}$ or involuntary regurgitation ${ }^{8,13}$ could be associated with tooth erosion presence.

Tooth erosion is a complex condition that is not well understood and due to its cumulative nature and interactions with other types of wear, important amounts of tooth structure can be loss ${ }^{15}$. Considering that several factors can influence the occurrence of erosive tooth wear, such as diet, for instance recently, higher prevalence of tooth erosion was associated with higher consumption of soft drinks and confectionary or snacks in children and adolescents ${ }^{16}$, more information from research studies with methodological quality is needed, to understand the dynamics of tooth erosion in early stages.

The aim of the study was to estimate the prevalence of tooth erosion and its association with socio demographic, clinical and behavioral factors in Brazilian schoolchildren.

\section{MATERIALS AND METHOD}

This study followed a cross-sectional design and was conducted in 2010 with children aged 8-12 years in Pelotas, a southern city of Brazil. The city has 328,275 inhabitants ${ }^{17}$ and nearly 25,628 are children with 8-12-years-old. Ethical approval (protocol n ${ }^{\circ} 60 / 2010$ ) was obtained from the Ethics Committee of the Federal University of Pelotas, Brazil. Parents or legal guardian signed a written informed consent before recruitment into the study. Detailed information about the methodology of this multi professional survey can be found elsewhere. ${ }^{18} \mathrm{~A}$ two-stage cluster sampling procedure was adopted. The first stage units were all elementary schools $(n=116$ : 25 private and 91 public schools) in the city and second stage units were the classrooms. For tooth erosion, the sample size (prevalence and association) was calculated using an assumed prevalence of tooth erosion of $13.0 \%{ }^{12}$, a sampling error of 4 percentage points, and a confidence level of $95 \%$. In addition, a design effect of 1.4 was applied, adding $20 \%$ to compensate refusals and $10 \%$ to control confounding factors (socioeconomic, clinical and behavioral). The minimum sample size was estimated to be 802 children. Schools were visited several times to avoid more than $10 \%$ of absence.

\section{Data collection}

Questionnaires, based on previous research, ${ }^{8}$ were pre-test and used by trained interviewers. Questions were related to children's age (complete years), gender, skin color (white, dark-skinned black, light-skinned black) ${ }^{17}$, type of school (private or public), mothers' education (categorized in- $\geq 12,9-11,5-8$ and $\leq 4$ ) and household income (collected in Brazilian Minimum Wage/month and later categorized into quintiles). Habits information was self-reported and included_tooth brushing frequency, recurrent vomiting, gastric upsets, consumption of drinks at night and food and drinks consumption frequency. Frequency was initially recorded at three levels: never, 1 or 2 times, and 3 times or more per week and later dichotomized in low ( 2 times per week or less) and high (3 times or more per week $)^{8,9}$. To assess the acidic cumulative effect, acidic food and drinks were re-organized to form 3 new variables: acidic food, acidic drinks and total acidic consumption (drinks plus food). The categories were dichotomized in low consumption (2 times per week or less) and high (3 times or more per week) ${ }^{19}$.

Clinical examinations were carried out at the selected schools and performed by six dentists with previous experience in oral health surveys, using proper individual protection equipment. Children were examined with sterilized mouth mirrors, CPI ("ball point") probes and gauze pads to clean and dry the tooth surface ${ }^{8,12}$, under artificial light and in a sitting position. Before the field work the examiners were trained and calibrated. The training phase included theoretical and practical background of concepts and details of tooth erosion. For the calibration exercise, the in lux method- based on the analysis and diagnosis of photographic images was used ${ }^{8,9,20}$. Tooth erosion was assessed by the modified O'Sullivan index ${ }^{12}$. Central maxillary incisors were analyzed through visual examination of facial, lingual, and incisal surfaces. For diagnosis, opaque, smooth with polished appearance surface, concave excavations, translucent incisal and "stand-up" restorations were use as clinical signs ${ }^{1,20}$. Inter-examiner kappa was obtain by the in lux method. For tooth erosion, inter-examiner kappa values ranged from 0.60 to 0.65 . Other clinical conditions were also evaluated: tooth trauma $\left(\mathrm{O}^{\prime} \text { Brien index }\right)^{21}$, enamel defects (Modified Developmental Defects of Dental Enamel index, DDE) ${ }^{22}$; plaque (Visible Plaque Index) ${ }^{23}$; dental caries (DMFT) ${ }^{24}$ and dental crowding (Dental Aesthetic Index , DAI) ${ }^{24}$. Clinical conditions, including tooth erosion, were dichotomized in absence and presence. Crowding was considered when the space between the right and left canine was insufficient to accommodate all four incisors in normal alignment.

\section{Data analysis}

Data were recorded in duplicate (Epi Info 6.0 software) and the analyses were carried out in Stata 12.0 (Stata Corp., College Station, TX, USA). Descriptive and bivariate analyses were performed to assess the association between predictor variables and the outcome using Pearson's chi-square test (sex, type of school, gastric upset, tooth brushing frequency, carbonated soft drinks, acid consumption, dental crowding, enamel defects, plaque and dental caries), or Linear Trend (age, household income, maternal schooling). All variables with $P$-value $<0.30$ in the bivariate analysis were considered potential confounders and were therefore included in the multivariate analysis, obtaining prevalence ratios (PR) and 95\% confidence intervals for the outcome. Multivariate analysis was performed through the Poisson regression, considering a conceptual model and temporal sequence of events (prevalence of tooth erosion) ${ }^{25}$. This model assesses disease determinants and in particular, how to handle the complex hierarchical inter-relationships between variables (distal, intermediate and proximal). In the distal level, the demographic and/or socioeconomic variables were included. For the intermediate level, behavioral characteristics were considered. In the proximal level, the children's biological characteristics were included. Explanatory variables were selected for the final models only if they had a $P$-value $\leq 0.05$ after adjustment. All of the analyses were weighted, allowing for the design effect of the sampling procedure using a Poisson regression model with robust variance and the "svy" commands for data from complex samples. 


\section{RESULTS}

A total of 1,210 children were enrolled in the study. The response rate was $69.3 \%$ of all invited children $(\mathrm{N}=1,744)$. The main reasons for non-participation were lack of parental consent $419(24.0 \%)$ and absence in the examination days 114 (6.7\%). Response rate between public and private schools was not different. The distribution of the sample according to predictors and outcome is presented in Table 1. Children were predominantly girls $(52.6 \%)$, white $(73.0 \%)$ and $79.0 \%$ of the total number of children attended public schools. Regarding maternal education, $53.0 \%$ studied 9 or more years.

The prevalence of tooth erosion was $25.1 \%$ (95\% CI: $23.4 ; 28.6)$. Erosive lesions were commonly presented in multiple surfaces in a single tooth (48.4\%). Lesions localized in enamel were $20.3 \%$, had matt appearance without any contour loss and presented less than a half of the surface affected $(64.6 \%)$, which indicates the lowest severity level.

Children had low consumption of natural juices and fruit and consumed soft drinks 3 times or more per week. The proportion of children consuming acid food and drinks at least 6 times a week was: $59.0 \%$ for drinks, $48.9 \%$ for food and $28.5 \%$ for both (drinks and food). Children with dental trauma, dental caries, enamel defects, presence of plaque and dental crowding were $12.7 \%$ (95\% CI: 11.0 ; 15.0), 32.5\% (95\% CI: 30.0; 35.1), 64.5\% (95\% CI: 62.0; 67.2), $90.0 \%$ (95\% CI: 88.0; 91.3) and 36.1\% (95\% CI: 33.4; 39.0) respectively.

Bivariate analysis is described in Table 2. Older children $(p=0.01)$, children who attended public schools $(p<0.01)$ and reported episodes of vomiting $(\mathrm{p}=0.011)$ had higher prevalence of erosion than their counterparts. Children with dental crowding showed lower erosive lesions than their counterparts $(p=0.026)$.

In Table 3, multivariate analysis revealed that children from public schools were statistically different (PR 1.73; 95\% CI: 1.06 ; 2.81) from those in private schools. In relation to age, children with 11 (PR: 2.03; 95\% CI: 1.23 ; 3.37) and 12 years old (PR:1.81; $95 \%$ CI: $1.04 ; 3.16$ ) had higher presence of tooth erosion than the younger ones. The presence of dental crowding was associated with lower prevalence of erosion (PR 0.78; 95\% CI: 0.61; 0.98).

Table 1 -Demographic, socio economic, biological and behavioral characteristics of schoolchildren. Pelotas, Brazil, $2010(n=1,211)^{*}$

\begin{tabular}{lrr}
\hline \multicolumn{1}{c}{ Variables/Category } & $\mathbf{n}^{*}$ & $\%$ \\
\hline Sociodemographic Characteristics & & \\
Sex & 1,211 & \\
Male & 574 & 47.4 \\
Female & 637 & 52.6 \\
Type of school & 1,211 & \\
Public & 958 & 79.0 \\
Private & 253 & 21.0 \\
Age (years) & 1,211 & \\
8 & 182 & 15.0 \\
9 & 312 & 26.0 \\
10 & 295 & 24.3 \\
11 & 259 & 21.3 \\
12 & 163 & 13.4
\end{tabular}

\begin{tabular}{lrr}
\hline \multicolumn{1}{c}{ Variables/Category } & $\mathbf{n}^{*}$ & $\%$ \\
\hline Household income (quintiles) & 1,037 & \\
1 (poorest) & 233 & 22.5 \\
2 & 197 & 19.0 \\
3 & 203 & 19.5 \\
4 & 223 & 21.5 \\
5 (richest) & 181 & 17.5 \\
Maternal schooling (years) & 1,176 & \\
$\geq 12$ & 502 & 43.0 \\
$9-11$ & 121 & 10.0 \\
$5-8$ & 127 & 11.0 \\
$\leq 4$ & 426 & 36.0
\end{tabular}

\section{Behavioral Habits}

Gastric upsets $\quad 1,195$

No $\quad 873$

73.1

Yes

6.6

Sometimes

20.3

Vomiting

81.5

No

1,193

972

3.2

Yes

15.3

Sometimes

183

Brushing frequency (daily)

1,185

1 time

58.8

2 times

697

9.0

3 times

32.2

Carbonated soft drinks (weekly)

Low

60.0

High

40.0

Acid Consumption (food and drinks)

Low

71.5

High

28.5

\section{Biological Characteristics}

Dental Crowding $\quad 1,202$

No $\quad 768$

64.0

Yes

434

Enamel defects $\quad 1,206$

No 430

36.0

Yes

36.0

Plaque

776

64.0

No

1,206

124

10.0

Yes

1,082

90.0

Dental caries

No

1,210

818

392

68.0

Yes

32.0

Tooth erosion $\quad 1,202$

No 900

74.9

Yes

25.1

*Values lower than 1211 due incomplete data 
Table 2 - Association between tooth erosion and demographic, socioeconomic, behavioral and biological factors in Brazilian schoolchildren. Pelotas, Brazil, $2010(n=1,211)$

\begin{tabular}{|c|c|c|c|c|c|c|c|}
\hline \multirow{2}{*}{ Variables/Category } & \multicolumn{3}{|c|}{ With Tooth erosion } & \multicolumn{3}{|c|}{ No Tooth erosion } & \multirow{2}{*}{$p$ value } \\
\hline & $\mathbf{n}$ & (\%) & Total + & $\mathbf{n}$ & $(\%)$ & Total++ & \\
\hline \multicolumn{8}{|l|}{ Sociodemografic Characteristics } \\
\hline Sex & & & 302 & & & 900 & $0.421^{*}$ \\
\hline Male & 149 & $(49.3)$ & & 420 & $(46.7)$ & & \\
\hline Female & 153 & $(50.7)$ & & 480 & $(53.3)$ & & \\
\hline Type of school & & & 302 & & & 900 & $<0.001^{*}$ \\
\hline Private & 41 & $(13.6)$ & & 210 & $(23.3)$ & & \\
\hline Public & 261 & $(86.4)$ & & 690 & $(76.7)$ & & \\
\hline Age (years) & & & 301 & & & 894 & $<0.001^{* *}$ \\
\hline 8 & 29 & $(9.6)$ & & 148 & $(16.6)$ & & \\
\hline 9 & 67 & $(22.3)$ & & 244 & $(27.2)$ & & \\
\hline 10 & 71 & $(23.6)$ & & 220 & $(24.6)$ & & \\
\hline 11 & 82 & $(27.2)$ & & 174 & (19.5) & & \\
\hline 12 & 52 & $(17.3)$ & & 108 & $(12.1)$ & & \\
\hline Household income (quintiles) & & & 263 & & & 762 & $0.026^{* *}$ \\
\hline 1 (poorest) & 65 & $(24.3)$ & & 166 & $(21.8)$ & & \\
\hline 2 & 62 & $(23.1)$ & & 133 & $(17.4)$ & & \\
\hline 3 & 52 & $(19.4)$ & & 150 & $(19.7)$ & & \\
\hline 4 & 50 & $(18.7)$ & & 173 & $(22.7)$ & & \\
\hline 5 (richest) & 39 & $(14.5)$ & & 140 & $(18.4)$ & & \\
\hline Maternal schooling (years) & & & 290 & & & 877 & $0.142^{* *}$ \\
\hline$\geq 12$ & 117 & $(40.3)$ & & 380 & $(43.3)$ & & \\
\hline $9-11$ & 24 & $(8.3)$ & & 97 & $(11.1)$ & & \\
\hline $5-8$ & 34 & $(11.7)$ & & 93 & $(10.6)$ & & \\
\hline$\leq 4$ & 115 & $(39.7)$ & & 307 & $(35.0)$ & & \\
\hline \multicolumn{8}{|l|}{ Behavioral Habits } \\
\hline Gastric upsets & & & 301 & & & 893 & $0.440^{*}$ \\
\hline No & 212 & $(70.4)$ & & 661 & $(74.0)$ & & \\
\hline Yes/sometimes & 89 & $(29.6)$ & & 232 & $(26.0)$ & & \\
\hline Vomiting & & & 301 & & & 891 & $0.011^{*}$ \\
\hline No & 242 & $(80.4)$ & & 730 & $(81.9)$ & & \\
\hline Yes & 3 & $(1.0)$ & & 35 & $(4.0)$ & & \\
\hline Sometimes & 56 & $(18.6)$ & & 126 & $(14.1)$ & & \\
\hline Brushing frequency (daily) & & & 291 & & & 885 & $0.548^{*}$ \\
\hline 1 time & 163 & $(56.0)$ & & 528 & $(59.7)$ & & \\
\hline 2 times & 28 & $(9.6)$ & & 78 & $(8.8)$ & & \\
\hline 3 times & 100 & $(34.4)$ & & 279 & $(31.5)$ & & \\
\hline Carbonated soft drinks (weekly) & & & 302 & & & 897 & $0.065^{*}$ \\
\hline Low & 168 & $(55.6)$ & & 553 & $(61.7)$ & & \\
\hline High & 134 & $(44.4)$ & & 344 & $(38.3)$ & & \\
\hline $\begin{array}{l}\text { Acid Consumption (food and } \\
\text { drinks) }\end{array}$ & & & 301 & & & & $0.229^{*}$ \\
\hline Low & 207 & $(68.8)$ & & 645 & $(72.4)$ & & \\
\hline High & 94 & (31.2) & & 246 & (27.6) & & \\
\hline
\end{tabular}


Prevalence and Associated Factors of Tooth Erosion in 8 -12-Year-Old Brazilian Schoolchildren

\begin{tabular}{|c|c|c|c|c|c|c|c|}
\hline \multirow{2}{*}{ Variables/Category } & \multicolumn{3}{|c|}{ With Tooth erosion } & \multicolumn{3}{|c|}{ No Tooth erosion } & \multirow{2}{*}{$p$ value } \\
\hline & $\mathbf{n}$ & (\%) & Total + & $\mathbf{n}$ & (\%) & Total++ & \\
\hline \multicolumn{8}{|l|}{ Biological characteristics } \\
\hline Dental Crowding & & & 302 & & & 900 & $0.026^{*}$ \\
\hline No & 210 & $(69.5)$ & & 562 & $(62.4)$ & & \\
\hline Yes & 92 & $(30.5)$ & & 337 & $(37.6)$ & & \\
\hline Enamel defects & & & 302 & & & 895 & $0.082^{*}$ \\
\hline No & 120 & (39.7) & & 306 & $(34.2)$ & & \\
\hline Yes & 182 & $(60.3)$ & & 589 & $(65.8)$ & & \\
\hline Plaque & & & 299 & & & 899 & $0.653^{*}$ \\
\hline No & 33 & $(11.0)$ & & 91 & $(10.1)$ & & \\
\hline Yes & 266 & $(89.0)$ & & 808 & (89.9) & & \\
\hline Dental Caries & & & 302 & & & 900 & $0.117^{*}$ \\
\hline No & 194 & $(64.2)$ & & 622 & $(69.1)$ & & \\
\hline Yes & 108 & $(35.8)$ & & 278 & $(30.9)$ & & \\
\hline
\end{tabular}

${ }^{*}$ Chi-square $\left(X^{2}\right)$ test ${ }^{* *} X^{2}$ test for linear trend + values lower than 301 and ++894 due incomplete data

Table 3-Crude (c) and adjusted (a) Prevalence Ratios (PR) for tooth erosion in Brazilian schoolchildren, according to sociodemographic, behavioral and biological factors. Pelotas, RS, Brazil. 2010.

\begin{tabular}{|c|c|c|c|c|}
\hline \multirow{2}{*}{ Variables/Category } & \multicolumn{4}{|c|}{ With tooth erosion } \\
\hline & \multicolumn{2}{|l|}{$\mathrm{PR}^{\mathrm{c}}(95 \% \mathrm{Cl}) \mathrm{p}^{*}$ value } & \multicolumn{2}{|l|}{$\mathrm{PR}^{\mathrm{a}}(95 \% \mathrm{Cl}) \mathrm{p}^{*}$ value } \\
\hline \multicolumn{5}{|c|}{ Level 1. Socio economic Characteristics } \\
\hline Type of school & & $<0.001$ & & 0.046 \\
\hline Private & 1.0 & & 1.0 & \\
\hline Public & $1.68(1.21: 2.33)$ & & $1.73(1.06 ; 2.81)$ & \\
\hline Age (years) & & $<0.001$ & & $<0.001$ \\
\hline 8 & 1.0 & & 1.0 & \\
\hline 9 & $1.31(0.85 ; 2.03)$ & & $1.40(0.84 ; 2.35)$ & \\
\hline 10 & $1.50(0.97 ; 2.31)$ & & $1.37(0.81 ; 2.30)$ & \\
\hline 11 & $1.95(1.27 ; 2.97)$ & & $2.03(1.23 ; 3.37)$ & \\
\hline 12 & $1.95(1.24 ; 3.07)$ & & $1.81(1.04 ; 3.16)$ & \\
\hline Household income (quintiles) & & 0.056 & & 0.531 \\
\hline 1 (poorest) & 1.0 & & 1.0 & \\
\hline 2 & $1.29(0.87 ; 1.92)$ & & $1.26(0.84 ; 1.91)$ & \\
\hline 3 & $1.45(0.98 ; 2.18)$ & & $1.15(0.76 ; 1.75)$ & \\
\hline 4 & $1.18(0.78 ; 1.80)$ & & $1.16(0.72 ; 1.69)$ & \\
\hline 5 (richest) & $1.03(0.68 ; 1.56)$ & & $1.26(0.82 ; 2.33)$ & \\
\hline Maternal schooling (years) & & 0.144 & & 0.990 \\
\hline$\geq 12$ & 1.0 & & 1.0 & \\
\hline $9-11$ & $0.84(0.54 ; 1.31)$ & & $0.85(0.52 ; 1.41)$ & \\
\hline $5-8$ & $1.14(0.78 ; 1.67)$ & & $1.05(0.68 ; 1.63)$ & \\
\hline$\leq 4$ & $1.16(0.89 ; 1.50)$ & & $0.95(0.67 ; 1.35)$ & \\
\hline \multicolumn{5}{|l|}{ Level 2. Behavioral habits } \\
\hline Soft drinks (weekly) & & 0.110 & & 0.384 \\
\hline Low & 1.0 & & 1.0 & \\
\hline High & $1.20(0.96 ; 1.51)$ & & $1.18(0.81 ; 1.71)$ & \\
\hline $\begin{array}{l}\text { Acidic consumption (food and } \\
\text { drinks) }\end{array}$ & & 0.299 & & 0.394 \\
\hline Low & 1.0 & & 1.0 & \\
\hline High & $1.14(0.89 ; 1.45)$ & & $1.25(0.74 ; 2.10)$ & \\
\hline
\end{tabular}

The Journal of Clinical Pediatric Dentistry Volume 41, Number 5/2017 
Table 3-Crude (c) and adjusted (a) Prevalence Ratios (PR) for tooth erosion in Brazilian schoolchildren, according to sociodemographic, behavioral and biological factors. Pelotas, RS, Brazil. 2010 (cont.).

\begin{tabular}{|c|c|c|c|c|}
\hline \multirow{2}{*}{ Variables/Category } & \multicolumn{4}{|c|}{ With tooth erosion } \\
\hline & \multicolumn{2}{|c|}{$\mathrm{PR}^{\mathrm{c}}(95 \% \mathrm{Cl}) \mathrm{p}^{*}$ value } & \multicolumn{2}{|c|}{$\mathrm{PR}^{\mathrm{a}}(95 \% \mathrm{Cl}) \mathrm{p}^{*}$ value } \\
\hline Gastric upsets & & 0.220 & & 0.360 \\
\hline No & 1.0 & & 1.0 & \\
\hline Yes/ Sometimes & $1.14(0.92 ; 1.41)$ & & $1.17(0.82 ; 1.67)$ & \\
\hline Vomiting & & 0.286 & & 0.544 \\
\hline No & 1.0 & & 1.0 & \\
\hline Yes & $0.32(0.10 ; 1.00)$ & & $0.68(0.21 ; 2.16)$ & \\
\hline Sometimes & $1.23(0.92 ; 1.65)$ & & $1.16(0.75 ; 1.80)$ & \\
\hline \multicolumn{5}{|l|}{$\begin{array}{l}\text { Level 3: Biological } \\
\text { Characteristics }\end{array}$} \\
\hline Enamel Defects & & 0.133 & & 0.175 \\
\hline No & 1.0 & & 1.0 & \\
\hline Yes & $0.84(0.66 ; 1.05)$ & & $0.85(0.67 ; 1.07)$ & \\
\hline Dental Caries & & 0.175 & & 0.568 \\
\hline No & 1.0 & & 1.0 & \\
\hline Yes & $1.18(0.93 ; 1.49)$ & & $1.07(0.84 ; 1.37)$ & \\
\hline Dental Crowding & & 0.055 & & 0.049 \\
\hline No & 1.0 & & 1.0 & \\
\hline Yes & $0.79(0.61 ; 0.97)$ & & $0.78(0.61 ; 0.98)$ & \\
\hline
\end{tabular}

*Heterogeneity test. Variables that presented $p>0.30$ in bivariate analysis were not included in multivariate analysis model.

\section{DISCUSSION}

This study found a prevalence of tooth erosion comparable to other studies performed in Southern Brazil. It was found to be associated with public school attendance and age, and children with dental crowding were less likely to have tooth erosion than their counterparts.

The prevalence of tooth erosion found in our study was $25.1 \%$, which is similar to rates from other studies performed with 12-year-old children 5, 9,14. Lower ${ }^{7,8,12,13}$ as well as higher 1, 2, 6, 11 prevalence have also been reported. One of the main reasons for the variability in prevalence rates between studies, could be related to the index used ${ }^{24}$, since none is universally accepted for tooth erosion ${ }^{6}$. We used the $\mathrm{O}^{\prime}$ Sullivan index because it was designed for epidemiologic surveys and provides information such as site, severity and affected surface area of erosive lesions ${ }^{8,11}$. In Brazil, this index was previously adapted and validated ${ }^{12}$ and it is the most common instrument used, allowing comparison between the results ${ }^{8,11}$. The present study assessed central maxillary incisors, the more frequently affected by tooth erosion ${ }^{5,6,9,10}$ and indicated to be "marker teeth" ${ }^{3,11}$. The evaluation of the "marker teeth" allows to save time during the screening procedure ${ }^{3}$ and control the overestimation ${ }^{12}$. The age group studied could also influence the prevalence of tooth erosion in children ${ }^{12}$. In this investigation, children aged 8-12-years were included. In this range of age, the acidic challenge may be sufficient to act against teeth ${ }^{9-11}$ and diagnosis confusion of tooth erosion could be minimized, since abrasion or attrition is unlikely to affect younger children ${ }^{9}$. Age was found to be a significant factor, comparable with other investigations ${ }^{3,8}$. Longitudinal studies have shown that the erosive process is cumulative and tend to progress with time, and individuals could not only develop new lesions but also the severity of existing lesions could progress ${ }^{2}$.
The severity of the erosive lesions in this study was low, as is usual in children and adolescents ${ }^{8-12,26} 25$ and is consistent with the limited time of exposure to risk factors of tooth erosion ${ }^{8,12}$. In this study, we found multi-surfaces with erosive wear in a single tooth, and this could be attributed to a drinking pattern of the acidic beverage, initially washed to the facial surface and the tongue, remaining in between the papillae after subsequent swallows to attack the enamel of the anterior teeth ${ }^{25}$. Generally, the palatal surface is the most affected by tooth erosion ${ }^{11}$ and authors pointed that the abrasive effects of the tongue on softened, demineralized enamel may contribute to a greater loss of tooth surface palatally ${ }^{6}$, thus results showed that acid can affect all surfaces of tooth.

The influence of socioeconomic characteristics in tooth erosion prevalence is unclear. Both a negative ${ }^{5,10}$ and positive ${ }^{6,7,11}$ relationship of tooth erosion with socioeconomic level has been reported. In Brazilian population, type of school has been used as a practical and feasible proxy for socioeconomic status ${ }^{27}$, considering that in private schools a mensal fee has to be paid ${ }^{7}$. In our study, children attending public schools presented higher prevalence of erosive tooth wear than those from private schools, similarly to previous report ${ }^{10,287}$. In our multifactorial analysis, acidic consumption was controlled for, so the explanation can't be found in the likelihood of public school children drinking more acidic drinks. Adolescents may experience more independence from their parents than younger children. Their lifestyles include less, or lack of, parental control in oral hygiene practices or in other behaviors, such as gastro-esophageal reflux or vomiting. These factors may be relevant for erosion development. ${ }^{10}$

Children with dental crowding presented significantly lower prevalence of tooth erosion than their counterparts, which is in agreement with a previous report ${ }^{2}$. It was proposed that the lack 
of alignment of teeth could increase pooling of saliva around teeth, promoting a protective effect ${ }^{2}$. However, crowding may also reduce the contact of the tongue (and tooth brush) with tooth surfaces, thus reducing the abrasive factor enhancing erosive wear.

Children and adolescents are consuming higher amounts of soft drinks ${ }^{29}$ and in Brazil almost one third of children consumed soft drinks at least 5 times a week ${ }^{19}$. The high consumption of soft drinks by children are related to unhealthy diet changes, which can influence the emergence of early general health problems such as obesity ${ }^{298}$, or in oral health increasing dental caries and tooth erosion ${ }^{2,6,10,14}$. In fact, recently it was reported that diet influence the prevalence of tooth erosion ${ }^{29}$. In the present study, high soft drinks consumption and high prevalence of tooth erosion were not associated, consistent previous studies ${ }^{7-9}$. This could be related to the method used to record diet in our study, since diet recording is complex and could influence the final results ${ }^{16}$ representing a limitation.

One of the main strengths of this study is related to the representative sample, selected by a two-stage random strategy involving schoolchildren from public and private schools of the city. The sample size was adequate allowing a considerable power of the study ${ }^{18}$. However, some limitations must also be addressed. The study followed a cross-sectional design, which prevents hypothesis of causality and temporal relations between the outcome and predictor variables $^{8}$. Cross-sectional studies are important tools to identify associated factors to be included in further longitudinal assessments ${ }^{8}$. The reliability of self-reporting dietary habits by schoolchildren is limited, since the possibility of under or over-reporting is real. Unfortunately, there is not a standardized questionnaire to assess acidic diet specific for tooth erosion that could be used in epidemiological surveys ${ }^{8}$. Differential diagnosis can be complex, especially at early stages as sustained for some authors ${ }^{8}$. Thus, Kappa values the inter-examiner agreement in our study above 0.6 were considered satisfactory as previously sustained, with kappa values between $0.6-0.8$ are considered substantial and $0.8-1$ perfect ${ }^{30}$.

In our study, children presenting moderate or severe erosive tooth wear were not observed. Therefore, this study corroborates that tooth erosion is not currently a public oral health problem in Brazilian children. However, since tooth erosion has a cumulative character, with time the incidence and the severity could increase. Thus, more longitudinal studies are needed to confirm these findings ${ }^{31}$.

Epidemiological studies, like the present study, enhance the consistency of findings and enlarged the evidence in the literature. The impact of tooth erosion on later life is not yet clear and the surveillance of such disorders is important.

Thus, the early implementation of actions to prevent or control predisposing factors and the monitoring of erosive lesions may be useful strategies to prevent future dental health problems, facilitating the targeting of resources of public health ${ }^{8}$.

\section{CONCLUSION}

This study showed that the prevalence of tooth erosion in children was high. The prevalence was higher in children with deprivated situation and in the older ones. Dental crowding was associated with lower presence of tooth erosion. Further epidemiological investigations are required in order to identify the pathways for the influence of socioeconomic background on the prevalence of tooth erosion in children. 


\section{REFERENCES}

1. El Aidi H, Bronkhorst EM, Huysmans MC and Truin GJ. Multifactorial analysis of factors associated with the incidence and progression of erosive tooth wear. Caries Res. 45: 303-12, 2011.

2. Dugmore CR and Rock WP. The progression of tooth erosion in a cohort of adolescents of mixed ethnicity. Int J Paediatr Dent. 13: 295-303, 2003.

3. Ganss C, Klimek J and Giese K. Dental erosion in children and adolescents - a cross-sectional and longitudinal investigation using study models. Community Dent Oral Epidemiol. 29: 264-71, 2001.

4. Tahmassebi JF, Duggal MS, Malik-Kotru G and Curzon ME. Soft drinks and dental health: a review of the current literature. J Dent. 34: 2-11, 2006.

5. Kazouilis S, Seow KW, Newman B, Ford D and Holcombe T. Common Dental Conditions Associated With Dental Erosion in Schoolchildren in Australia. Pediatric Dentistry. 29, 2007.

6. Bardsley PF, Taylor S and Milosevic A. Epidemiological studies of tooth wear and dental erosion in 14-year-old children in North West England. Part 1: The relationship with water fluoridation and social deprivation. $\mathrm{Br}$ Dent J. 197: 413-6; discussion 399, 2004.

7. Gurgel CV, Rios D, Buzalaf MA, et al. Dental erosion in a group of 12- and 16-year-old Brazilian schoolchildren. Pediatric dentistry. 33: 23-8, 2011.

8. Vargas-Ferreira F, Praetzel JR and Ardenghi TM. Prevalence of tooth erosion and associated factors in 11-14-year-old Brazilian schoolchildren. J Public Health Dent. 71: 6-12, 2011.

9. Correr GM, Alonso RC, Correa MA, Campos EA, Baratto-Filho F and Puppin-Rontani RM. Influence of diet and salivary characteristics on the prevalence of dental erosion among 12-year-old schoolchildren. Journal of dentistry for children (Chicago, Ill). 76: 181-7, 2009.

10. Al-Dlaigan YH, Shaw L and Smith A. Dental erosion in a group of British 14-year-old, school children. Part I: Prevalence and influence of differing socioeconomic backgrounds. Br Dent J. 190: 145-9, 2001.

11. Mangueira DF, Sampaio FC and Oliveira AF. Association between socioeconomic factors and dental erosion in Brazilian schoolchildren. J Public Health Dent. 69: 254-9, 2009.

12. Peres KG, Armenio MF, Peres MA, Traebert J and De Lacerda JT. Dental erosion in 12-year-old schoolchildren: a cross-sectional study in Southern Brazil. Int J Paediatr Dent. 15: 249-55, 2005.

13. Van Rijkom HM, Truin GJ, Frencken JE, et al. Prevalence, distribution and background variables of smooth-bordered tooth wear in teenagers in the hague, the Netherlands. Caries Res. 36: 147-54, 2002.

14. Wang P, Lin HC, Chen JH and Liang HY. The prevalence of dental erosion and associated risk factors in 12-13-year-old school children in Southern China. BMC Public Health. 10: 478, 2010.

15. El Aidi H, Bronkhorst EM, Huysmans MCDNJM and Truin GJ. Multifactorial analysis of factors associated with the incidence and progression of erosive tooth wear. Caries Research. 45: 303-12, 2011.
16. Salas MM, Nascimento GG, Vargas-Ferreira F, Tarquinio SB, Huysmans $\mathrm{MC}$ and Demarco FF. Diet influenced tooth erosion prevalence in children and adolescents: Results of a meta-analysis and meta-regression. J Dent. 43:865-875, 2015

17. IBGE. Características da população e domicílios-Resultados do UniversoNotas metodológica. Rio de Janeiro,: IBGE(Brazilian Institute of Geographic and Statistics). 2010.

18. Goettems ML, Correa MB, Vargas-Ferreira F, et al. Methods and logistics of a multidisciplinary survey of schoolchildren from Pelotas, in the Southern Region of Brazil. Cad Saude Publica. 29: 867-78, 2013.

19. IBGE. Pesquisa Nacional de Saúde do Escolar. Rio de Janeiro: Brazilian Institute of Geographic and Statistics, 2009.

20. O'Sullivan EA. A new index for the measurement of erosion in children. :. Eur J Paediatr Dent 2: 69-74, 2000.

21. O'Brien M. Children's Dental Health in the United Kingdom 1993. Londres: Her Majesty's Stationery Office, 1994.

22. A review of the developmental defects of enamel index (DDE Index). Commission on Oral Health, Research \& Epidemiology. Report of an FDI Working Group. Int Dent J. 42: 411-26, 1992.

23. Ainamo J and Bay I. Problems and proposals for recording gingivitis and plaque. Int Dent J. 25: 229-35, 1975.

24. World, Health and Organization. Oral health surveys-basic methods. 4th ed. Geneva1997.

25. Victora CG, Huttly SR, Fuchs SC and Olinto MT. The role of conceptual frameworks in epidemiological analysis: a hierarchical approach. Int $\mathrm{J}$ Epidemiol. 26: 224-7, 1997.

26. Larsen MJ, Poulsen S and Hansen I. Erosion of the teeth: prevalence and distribution in a group of Danish school children. European journal of paediatric dentistry : official journal of European Academy of Paediatric Dentistry. 6: 44-7, 2005.

27. Piovesan C, Padua MC, Ardenghi TM, Mendes FM and Bonini GC. Can type of school be used as an alternative indicator of socioeconomic status in dental caries studies? A cross-sectional study. BMC medical research methodology. 11: 37, 2011.

28. Dugmore CR and Rock WP. The prevalence of tooth erosion in 12-year-old children. Br Dent J. 196: 279-82; discussion 3, 2004.

29. Vartanian LR, Schwartz MB and Brownell KD. Effects of soft drink consumption on nutrition and health: a systematic review and meta-analysis. Am J Public Health. 97: 667-75, 2007.

30. McHugh ML. Interrater reliability: the kappa statistic. Biochemia medica. 22: 276-82, 2012.

31. Vargas-Ferreira F, Piovesan C, Praetzel JR, Mendes FM, Allison PJ and Ardenghi TM. Tooth erosion with low severity does not impact child oral health-related quality of life. Caries Res. 44: 531-9, 2010. 